\title{
THE IMPORTANCE OF INTEGRATING
}

\section{GLOBAL HEALTH AND ORAL HEALTH:} WHAT CAN WE LEARN FROM THE COVID-19 PANDEMIC IN THE UK?

\section{By Arunika Nehra and Caroline}

Tharakan, Leeds

Dental Institute

\section{Key Points \\ - Highlights the importance of incorporating oral health care into universal health coverage \\ - Informs of the implications of COVID-19 on dental care \\ - Reflects on the limitations of government action on dental services \\ - Provides insight into future considerations in preparation for subsequent global health crises}

\section{Abstract}

The COVID-19 pandemic has been widely noted as the worst global health challenge faced for a century. Healthcare systems across the world have been gravely impacted and progress of global sustainable development goals (SDGs) threatened. The COVID-19 pandemic was not the first, and certainly not the last, global health emergency. Therefore, it is important for future responses to address the shortcomings of past experiences. Oral healthcare systems (OHCS) have consistently been overlooked in global health responses and awareness of global health challenges amongst the dental community is limited. The COVID-19 pandemic has demonstrated the invaluable contribution of OHCS, and the important role dental healthcare professionals (DHCP) can play in any global health emergency. Hopefully it sets a precedent

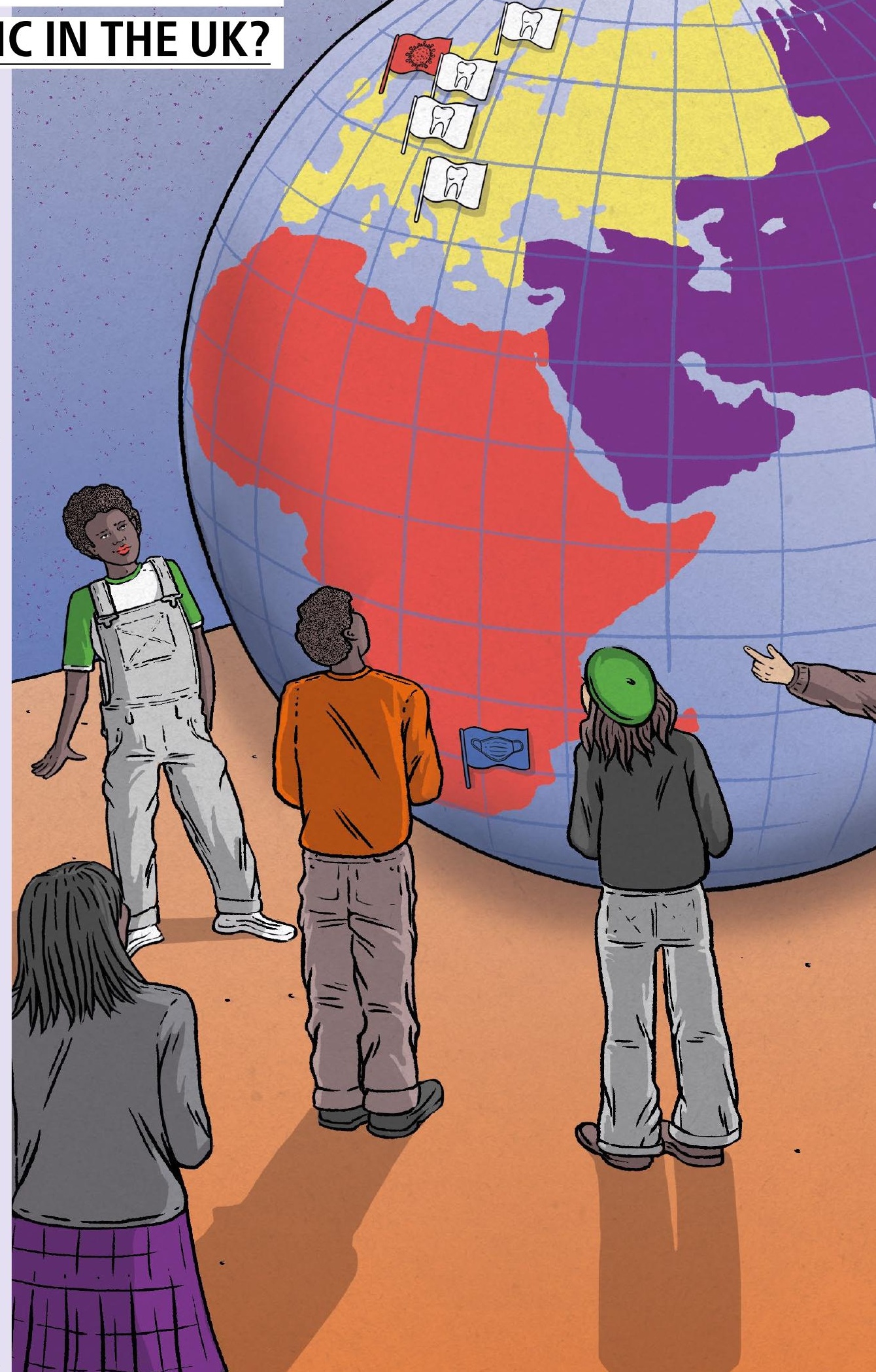




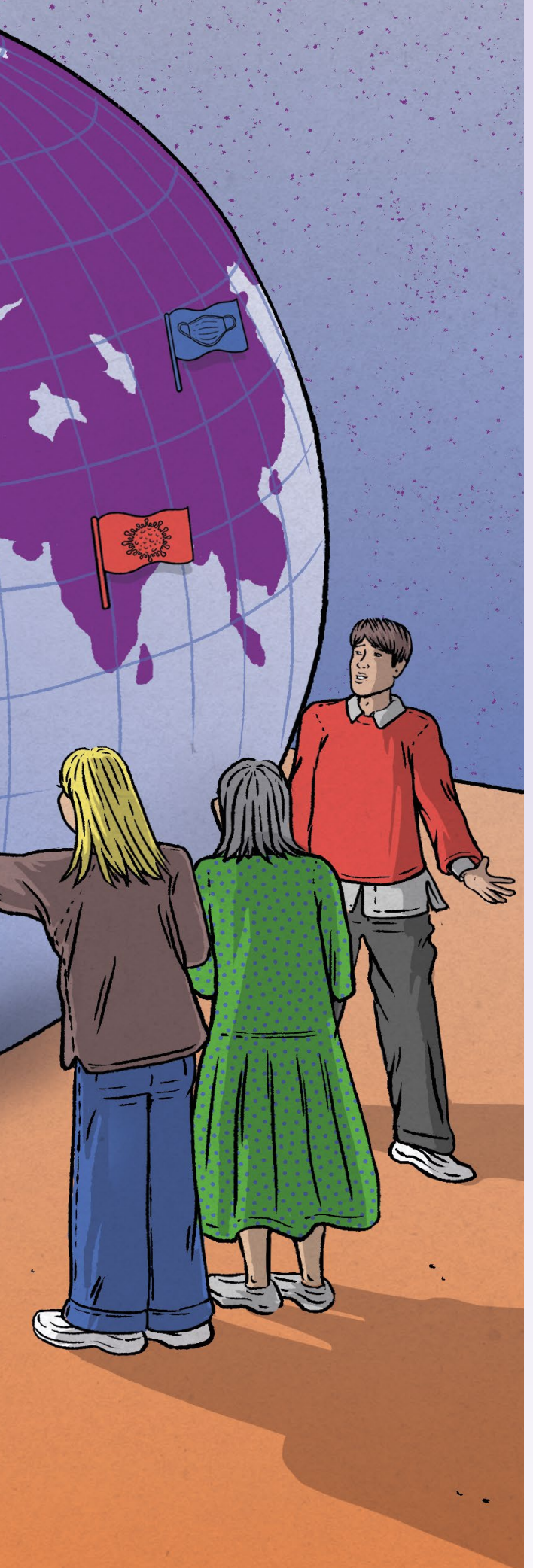

for future global health challenges and strengthens the integration of oral health and global health.

\section{Background}

The World Health Organisation (WHO) announced a global public health emergency on 30 January 2020 after the emergence of a viral pneumonia outbreak. ${ }^{1}$ The infectious agent was identified as a novel coronavirus (COVID-19) and a pandemic was declared on 11 March $2020 .^{2}$ DHCPs were identified as having higher exposure to contagion and infection transmission, as a result of close contact with the patient's oral cavity and the presence of bacteria and viruses in aerosols created by dental instrumentation. ${ }^{3}$ Due to this increased exposure, DHCPs were claimed to be at high risk of acquiring COVID-19 or becoming carriers of the virus and spreading it. ${ }^{4}$ To minimise infection risk, on 25 March 2020, UK dental practices were ordered to suspend all routine and non-urgent dental care, and establish a remote urgent care service to provide telephone triage using the AAA protocol (advice, analgesic and antibiotics). The patients for whom this approach was ineffective were referred to urgent dental care centres (UDCC) for dental intervention. Many DHCPs volunteered to help the response and were redeployed across NHS services. As of 8 June 2020, dental practices reopened and were able to provide routine treatment under COVID-19-related safety measures, but have had to deal with severe financial repercussions and backlog of patients requiring routine dental care. ${ }^{5}$

\section{Global health and oral health}

The COVID-19 pandemic has had staggering social and economic costs, exacerbated existing inequities, as well as having a profound impact on global healthcare systems. ${ }^{6}$ The 2030 Agenda for Sustainable Development, adopted by all United Nations (UN) Member States in 2015, aims to improve global healthcare through targets ranging from reducing poverty and noncommunicable disease (NCDs) to achieving universal health coverage (UHC). Although global leaders were already off-track to deliver the SD Goals by 2030, the COVID-19 pandemic has stalled the progress further and threatens the achievements already made. ${ }^{7}$

The WHO recently released a COVID-19 strategic preparedness and response plan for the upcoming year, ${ }^{8}$ in which they reflect on what we have learnt from the pandemic response and they translate this into future response planning. It is important for global health efforts to be efficient and resilient, such that they reflect the evolving needs and emerging challenges of the health crisis. In order to do so, it is pivotal to learn from past experiences. The COVID-19 pandemic was unprecedented in many ways, but it most definitely was not unexpected.

Historically, there have been numerous past and ongoing global health crises - the HIV pandemic, H1N1 pandemic and the Ebola epidemic in West Africa - all of which had profound impacts on global systems and also provided pivotal learning experiences.

\section{'Dental practices have been reported to operate at less than a quarter of pre-COVID-19 capacity'}

The COVID-19 pandemic response serves as a stark reminder that even the most resilient health systems can be overwhelmed, therefore highlighting the importance of strengthening national healthcare systems. Any global crisis effort requires coordinated multi-sectoral actions at global, national and regional levels ${ }^{9}$ across all public health systems, including oral healthcare systems. Oral health has always been an overlooked aspect of global health. Oral diseases are mostly preventable, yet are rampant across all countries and affect $60-90 \%$ of the population. ${ }^{10}$ Oral health was omitted from the SDGs, despite oral diseases being closely linked to SDG 3 and sharing common risk factors with NCDs. ${ }^{11}$ The UN took a step in the right direction when they recognised oral diseases as a major global health burden and oral health was included in the Political Declaration on UHC. ${ }^{12}$ However, despite UHC gaining considerable momentum and becoming a priority area in reaching SDGs, oral health has been mostly absent from the UHC discussions, with limited progress made in addressing global oral diseases. The importance of strengthening the integration of oral health into UHC has been strongly urged, as well as the inclusion of OHCS in essential healthcare. ${ }^{13,14}$ 
Impact of COVID-19 on dental care The COVID-19 pandemic has had catastrophic impacts on the National Health Service (NHS) and caused severe disruptions to the provision of dental services, as well as access to dental care. In our opinion, the response seriously overlooked and mishandled NHS dentistry, resulting in devastating impacts on oral health and sustainability of dental practices.

\section{Access to dental care}

The closure of dental practices severely limited access to dental services, with reports showing that access to dental care has more than halved and 19 million fewer dental appointments have been undertaken. The implementation of COVID-19 restrictions to assist the opening of dental practices has significantly reduced the capacity to treat patients. This is largely due to the need for infection control measures, namely the introduction of fallow time between appointments, as well as the time required to comply with PPE requirements and social distancing measures. Dental practices have been reported to operate at less than a quarter of pre-COVID-19 capacity. The restricted access of dental services has resulted in a substantial backlog of patients requiring essential dental care. Dental services must grapple with balancing routine treatments and urgent

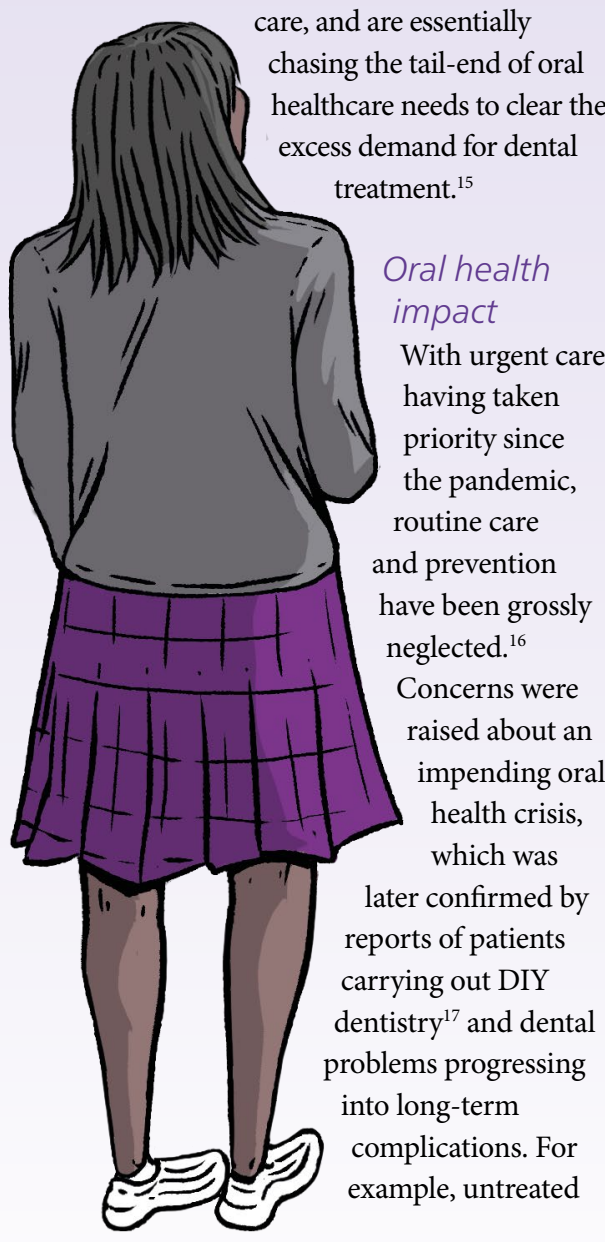

dental problems, initially deemed as nonurgent - such as loss of a restoration - have the potential of progressing into further decay and pulpal involvement, and eventually at risk of becoming unrestorable. ${ }^{15}$ Additionally, routine dental care is also vital for oral cancer screening and diagnosing it at an early stage. Reports have shown cancer referrals have decreased since the pandemic, highlighting the potential risk of oral cancers being undiagnosed..$^{18}$ Furthermore, there has been a stark increase in remotely prescribed antibiotics, due to the AAA protocol implemented. This has caused serious oral health ramifications and wider health implications, with patients having been reported to return with pain or further swelling since the root cause of the dental problem was not addressed. Alongside this, the over-prescription of antibiotics has accelerated antimicrobial resistance, which is already a major public health burden and one of the biggest threats to global health. ${ }^{19}$

\section{Financial implications}

The COVID-19 pandemic has seriously questioned the financial stability of NHS dental services as a whole. NHS and private dental businesses in particular have been under vast monetary pressures, with a continuing struggle to balance the safety and provision of dental care. Initially, support was only available for dental practices offering NHS treatment. However most dental businesses are mixed - providing NHS and private work - and therefore, this posed significant financial constraints for the private component of these practices. Wholly private practices especially suffered, with many finding it nearly impossible to keep afloat, mainly due to loan repayments and PPE costs. ${ }^{20}$ Dental unions have since relentlessly lobbied to get the private dental sector's voice heard, and to be included in fiscal support measures. ${ }^{21}$ Furthermore, dental practices have been faced with an increase in punitive NHS activity targets, burdening practices with severe financial pressures and compromising their sustainability. ${ }^{22}$

\section{Dental workforce response}

With dental practices ceasing all routine care, there was a freed capacity of a highly skilled dental workforce to provide much needed support to the wider COVID-19 response. An army of DHCPs rose to the challenge to support the pandemic response efforts and were redeployed to assist frontline care services and take on auxiliary roles beyond their usual scope of practice.

This included working in UDCC, local authorities and voluntary services. Moreover, the dental workforce also made flexible use of their non-dental clinical skills. Many volunteered to support NHS Test and Trace, which required considerable personnel resources and was integral for controlling the spread of the virus. Additionally, once vaccinations emerged, DHCPs were also called upon to support the mass vaccination efforts and established themselves as key members of the immunisation workforce. ${ }^{23,24}$

\section{'Despite the dental workforce eventually being included in the definition of essential workers, they still faced challenges'}

\section{Shortcomings}

The government was faced with many difficult decisions and there was a period of uncertainty for the dental sector. Although there were regular updates by Public Health England, there was a lack of clear communication, guidance and support. First and foremost, there was grave miscommunication by the WHO which stated in their guidance that routine dental care was regarded as non-essential, yet conversely emphasised the importance of effective prevention during the pandemic. The term 'non-essential' was later reworded to 'nonurgent,' however there was still an upheaval about the possible misinterpretation of the guidance, its inapplicability to the UK setting, and the lack of clarity regarding the definition of essential dental services. ${ }^{14}$

Further ambiguity was witnessed in the failure to provide clarity on the key worker status of the dental sector. Despite the dental workforce eventually being included in the definition of essential workers, they still faced challenges in being recognised as critical workers and were overlooked in government support efforts. ${ }^{15}$ Overall, the pandemic response has gravely undermined the sustainability of the dental sector, alongside the detrimental impact of the pandemic on oral health. 
With the potential global and national resurgence of COVID-19, there will be imminent pandemic-related limitations and challenges that will impact the delivery and access to dental services. ${ }^{25}$ There needs to be a better understanding of oral health implications during global and national health challenges. The dental profession needs to be adequately supported to effectively respond to the needs of patients, and more importantly, to appropriately recuperate from their financial burdens.

\section{Future considerations}

The COVID-19 pandemic can be seen as a vital opportunity to reform dentistry. OHCS should not be treated in isolation from mainstream healthcare systems. Oral health care must be included as essential healthcare and DHCPs viewed holistically as part of the wider healthcare workforce. A more integrated model of care is required, with OHCS cognisant of global health responses. ${ }^{26}$

Conversely, it is also important to increase global health awareness within dentistry. Currently there is limited implementation of global health learning in dental education. ${ }^{27}$ It can be beneficial to include global health teaching as continual professional development (CPD), as well as within the dental undergraduate curriculum. It is imperative that DHCPs have the knowledge and understanding of global health concepts to be able to manage the continually evolving nature of COVID-19 and the eventuality of future global health crises.

\section{Conclusion}

Oral diseases are a major global health concern, yet oral health is a neglected area in global health. The COVID-19 pandemic has brought to light the negative impact global health crises can have on oral healthcare needs. There is an urgent call for increased funding to support the integration of oral health in sustainable healthcare models and protect populations' oral health during global health challenges.

The pandemic has also highlighted the positive contribution of the dental workforce towards general health and public protection. Utilising the breadth of skills the dental workforce can offer in wider healthcare system efforts is imperative for strengthening the capacity to provide concerted and resilient responses.

\section{Acknowledgement}

Thanks to David A. H. Scott, BDS, MPH, Academic Clinical Fellow in Dental Public Health, University of Dundee

\section{References}

1. Zhou P, Yang X L, Wang X G et al. A pneumonia outbreak associated with a new coronavirus of probable bat origin. Nature 2020; 579: 270-273.

2. World Health Organisation WHO Director-General. Speeches. Detail. WHO Director-General's opening remarks at the media briefing on COVID-19. 11 March 2020. Available online at: www.who.int/directorgeneral/speeches/detail/ who-director-general-s-openingremarks-at-the- media-briefingon-covid-19---11-march-2020 (Accessed July 2021)

3. Checchi V, Bellini P, Bencivenni D and Consolo U. COVID-19 Dentistry-Related Aspects: A Literature Overview. Int Dent $J$ 2021; 71: 21-26.

4. Coulthard P. Dentistry and coronavirus (COVID-19) moral decision-making. Br Dent J 2020; 228: 503-505.

5. British Dental Association. Live updates: Coronavirus and dentistry. June 2020. Available online at: https:// bda.org/advice/Coronavirus/Pages/latest-updates.aspx (Accessed June 2021).

6. World Bank. The global economic outlook during the COVID-19 pandemic: a changed world. Available online at: www.worldbank.org/en/news/ feature/2020/06/08/the-global-economic-outlookduring-the-covid-19-pandemic-a-changed-world (Accessed July 2021)

7. Min Y and Perucci F. UN/DESA Policy Brief \#81: Impact of COVID-19 on SDG Progress: A Statistical Perspective. Available online at: www.un.org/ development/desa/dpad/publication/un-desa-policybrief-81-impact-of-covid-19-on-sdg-progress-astatistical-perspective/ (Accessed July 2021).

8. World Health Organisation. COVID-19 STRATEGIC PREPAREDNESS AND RESPONSE PLAN. Available online at: www.who.int/publications/i/item/WHOWHE-2021.02 (Accessed July 2021)

9. Chen Z, Cao C and Yang G. Coordinated multi-sectoral efforts needed to address the COVID-19 pandemic: lessons from China and the United States. Glob Health Res Policy 2020; 5: 22

10. Kassebaum N J, Bernabé E, Dahiya M et al. Global burden of untreated caries: a systematic review and metaregression. J Dent Res 2015; 94: 650-658.

11. World Health Organisation. Oral health and non-communicable diseases. Available online at: https://www.euro.who.int/en/health-topics/diseaseprevention/oral-health/policy/oral-health-andnoncommunicable-diseases (Accessed July 2021).

12. United Nations. Political Declaration of the High-level Meeting on Universal Health Coverage 'Universal health coverage: moving together to build a healthier world'. 2019. Available online at: www.un.org/pga/73/ wp-content/uploads/sites/53/2019/07/FINAL-draftUHC-Political-Declaration.pdf (Accessed July 2021).

13. Wang T T, Mathur M R and Schmidt H. Universal health coverage, oral health, equity and personal responsibility. Bulletin of the World Health Organisation 2020; 98: 719-721.

14. Benzian H, Beltrán-Aguilar E, Mathur M R and Niederman R. Pandemic considerations on essential oral health care. J Dent Res 2021; 100: 221-225.

15. House of Commons Library: Research Briefing by Kulakiewicz A, Baker C and Macdonald M. and Baker. Effect of covid-19 on dental services. Available online at: https://commonslibrary.parliament.uk/researchbriefings/cdp-2021-0001/ (Accessed July 2021).

16. Zachary B D and Weintraub J A. Oral Health and COVID-19: Increasing the Need for
Prevention and Access. Prev Chronic Dis 2020; 17: e82.

17. BBC News. Coronavirus: man refused appointment pulls out tooth at home. 18 April 2020. Available online at: www.bbc.co.uk/news/uk-england-devon-52321910 (Accessed July 2021).

18. Oral Health Foundation. State of Mouth Cancer UK Report 2020/2021. Available online at: www.dentalhealth.org/Handlers/Download. ashx?IDMF=08b28d55-f52f-4b21-a 9a0-342d041c5d0c (Accessed July 2021).

19. Shah S, Wordley V and Thompson W. How did COVID-19 impact on dental antibiotic prescribing across England?. Br Dent J 2020; 229: 601-604.

20. Coulthard P, Thomson P, Dave M et al. The COVID19 pandemic and dentistry: the clinical, legal and economic consequences - part 2: consequences of withholding dental care. Br Dent J 2020; 229: 801-805.

21. British Dental Association. Speaking up for the profession. Available online at: https://bda.org/ makingadifference (Accessed July 2021).

22. British Dental Association. Dentists: NHS Targets rise as 1 in 10 practices face 'cliff edge'. Available online at: www.bda.org/news-centre/press-releases/Pages/ Dentists-NHS-Targets-rise-as-1- in-10-practices-facecliff-edge.aspx (Accessed July 2021).

23. National Health Services. Redeploying the Clinical Dental Workforce to Support the NHS Clinical Delivery Plan for COVID-19, Version 2. Available online at: www.england.nhs.uk/coronavirus/wp-content/ uploads/sites/52/2020/04/C0301-PermissionsRedeploying-our-people-clinical-dental-workforce-v2. pdf (Accessed July 2021).

24. Hiscott G. COVID-19 vaccination - dental professionals' moral duty to help. Available online at: https://dentistry.co.uk/2021/01/15/covid-19vaccination/ (Accessed July 2021).

25. National Health Services. COVID-19 guidance and standard operating procedure. Version 3. Available online at: www.england.nhs.uk/coronavirus/ wp-content/uploads/sites/52/2020/06/C0581- covid19-urgent-dental-care-sop-update-16-june-20-.pdf (Accessed July 2021).

26. Seneviratne C J, Lau M W J and Goh B T. The role of dentists in COVID-19 is beyond dentistry: voluntary medical engagements and future preparedness. Front Med 2020; 7: 566

27. Seymour B, Shick E, Chaffee B and Benzian H. Going Global: Toward Competency-Based Best Practices for Global Health in Dental Education. J Dent Educ 2017; 81: 707-715.

https://doi.org/10.1038/s41406-021-0242-2 